\title{
Research Paper: The Role of Mindfulness, Spiritual Experiences, and Coping Strategies in Anticipation of the Quality of Life of Patients With Tuberculosis
}

\author{
Somayeh Nakhaei ${ }^{1}$ (D), Mojtaba Amiri Majd²* ${ }^{*}$, Alireza Mohammadi Arya ${ }^{3}$ (D), Mahmoud Shirazi ${ }^{4}$ (D) \\ 1. Department of Psychology, Faculty of Human Sciences, Zabol Branch, Islamic Azad University, Zabol, Iran. \\ 2. Department of Psychology, Faculty of Human Sciences, Abhar Branch, Islamic Azad University, Abhar, Iran. \\ 3. Department of Preschool Education, School of Education Sciences and Social Welfare, University of Social Welfare and \\ Rehabilitation Sciences, Tehran, Iran. \\ 4. Department of Psychology, Faculty of Educational and Psychology, University of Sistan and Baluchestan, Zahedan, Iran.
}

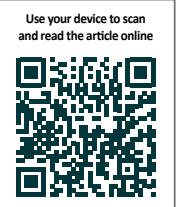

Criation Nakhaei S, Amiri Majd M, Mohammadi Arya A, Shirazi M. The Role of Mindfulness, Spiritual Experiences, and Coping Strategies in Anticipation of the Quality of Life of Patients With Tuberculosis. Journal of Research \& Health. 2020; 10(3):143150. http://dx.doi.org/10.32598/JRH.10.3.1402.1

doi : http://dx.doi.org/10.32598/JRH.1

\section{(i) (9)}

Article info:

Received: 29 Apr 2018

Accepted: 20 Jan 2019

Publish: 01 May 2020

\section{Keywords:}

Quality of life, Mindfulness, Tuberculosis

\begin{abstract}
Background: The purpose of this study was to determine the role of mindfulness, spiritual experiences, and coping strategies in predicting the quality of patients' life with Tuberculosis (TB).

Methods: The present research is a correlational study and the statistical population comprised all TB patients referred to the Tuberculosis Center in Zabol City, Iran. A sample of 100 people was selected randomly, and they answered the five factorial mindfulness questionnaire, Bonab spiritual experiences scale, Lazarus and Folkman ways of coping questionnaire, and the World Health Organization quality of life scale.

Results: The obtained data were analyzed by using correlation matrix and multiple regressions. The results showed a significant and positive relationship between mind-awareness and quality of life, and this variable could predict $38 \%$ and the spiritual experiences $27 \%$ and problemoriented coping strategies $5.2 \%$ of the life quality variance.

Conclusion: There is a negative and significant relationship between emotional coping strategies and quality of life. Given that psychological factors can be predictors of quality of life, they should be taken into consideration in therapeutic planning.
\end{abstract}

\section{Introduction}

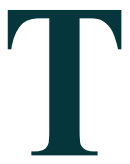

uberculosis (TB) is one of the most important infectious diseases of this century capable of involving all organs of the body, but most likely the lungs get infected. It is mainly a chronic disease. The term "chronic pain" is used to describe an intractable pain, which lasts longer than usually expected to treat the source of pain [1]. Chronic pains, as well as physical and psychological disabilities, impose remarkable costs on the economic resources of countries. The economic cost of chronic pain alone is more than the total costs of heart disease, cancer, and AIDS.

\section{* Corresponding Author:}

Mojtaba Amiri Majd, PhD.

Address: Department of Psychology, Faculty of Human Sciences, Abhar Branch, Islamic Azad University, Abhar, Iran.

Phone: +98 (915) 4195118

E-mail:amirimajd@abhariau.ac.ir 
Humans have suffered from tuberculosis for many years. TB is seen all around the world and in all ages [2]. TB changes into a chronic disease and undermines the quality of life in patients. Today, with increasing life expectancy, other important factors such as lifestyle or quality of life are emphasized. According to the World Health Organization (WHO), the quality of life refers to the perception of individuals from their place in life, regarding the cultural context of their society, objectives, and concerns as a result of variables such as physical health, psychological status, independence, and social relationships [3]. Quality of life is individuals' perception of their position in life, in cultural areas and value systems which corresponds to their objectives, expectations, and standards [4]. Quality of life is associated with the mental health of individuals and expresses their moods and changes and capabilities as well as their satisfaction with life performance [5].

Nowadays, particular attention is being paid to the capacities that play an important role in the quality of life. One of these components is spirituality which is a kind of internal consciousness and a sense of connection between oneself and the surrounding world. Vegan knows spirituality as the highest level of growth in areas such as cognition, ethics, and emotion among individuals and considers it as an attitude, including peak experiences of growth. The studies of Moalemi et al [6], and Hosseindokht et al. [3] indicated that spirituality is positively associated with physical and mental health. The proponents of the role of spirituality in the improvement of mental health and interpersonal compatibility have made numerous attempts to build a link between the concept of health and spirituality under the title of spiritual wellbeing. The findings of Ghofrani [7] concerning the role of spiritual intelligence in the quality of life showed that spiritual intelligence has an effective role in predicting the quality of life. Allah Bakhshian et al. [8] researched about spiritual health and quality of life in patients with Multiple Sclerosis (MS). The results showed a significant relationship between spiritual health and quality of life, so the need to strengthen the spiritual dimension of health as a factor affecting the patients' quality of life could be understood.

Another concept in the field of mental health which has gained a special place is mindfulness-based intervention. Mindfulness is the receptive and non-judgmental awareness of what is happening right now. Mindfulness-based intervention is a kind of systematic and intensive approach which is used for acquiring new kinds of control and wisdom based on internal capabilities for relaxation, attention, knowledge, and insight. Mindfulness was em- phasized in the West since the 1970s [9]. According to Kabat-Zinn [10], the useful coping strategies of mindfulness for creating and maintaining awareness include release, patience, persistence, primer mind, disengagement, acceptance, and lack of evaluation judgment.

The findings of Sajadiyan [11] showed that this kind of intervention is effective for treating both psychological and physical symptoms. The findings of Heidari et al. [12] showed the importance of mindfulness, emotional intelligence, and general self-efficacy in predicting and reducing perceived stress. Results of Babaei et al. [13] showed a positive and significant correlation between mindfulness and positive emotional-cognitive regulation. Duan [14] research on mindfulness and its role in reducing stress and mental health, suggests that training mindfulness can recognize the strengths and weaknesses of the care providers. Also, it can be an effective factor in improving mental health, increasing individual well-being, and reducing stress. Bamber and Schneider [15] study on the effect of mind-awareness in reducing student's anxiety revealed that the higher level of consciousness would reduce the level of stress in a person.

Another important concept in the quality of life is the coping strategy. Psychology of health considers coping strategy a critical concept in relation to physical and mental health and regards it as the most widespread subject matter in contemporary psychology, as well as one of the most important psychological and social factors that interfaces between stress and the disease [16]. Coping strategies are a set of cognitive and behavioral attempts of an individual to interpret and modify a stressful situation and reduces the suffering caused by that [17]. Nejadhomadi and Moradi [18] found that the variables of mind-awareness, problem-oriented coping strategies, and excitementoriented systems could predict the life quality in cancer patients. Heydari et al. [12] showed a positive and significant relationship between life quality and spirituality.

Nohi [19] reported a significant and negative relationship between quality of life and emotional coping strategies, and a significant and positive relationship between quality of life and problem-oriented coping methods. Tamizi et al. [17] indicated that the majority of research samples (42.1\%) used the "avoidance coping strategy," and the majority of research samples had a moderate quality of life. The results showed a significant relationship between the mean quality of life scores and the type of coping strategies so that the research samples who used more avoidance coping strategies had a lower overall mean score in quality of life. 
The results of the studies conducted on the relationship between variables are very controversial. Many scientists such as Azad Marzabadi et al. [20] have emphasized the effect of religion and spirituality on individuals dealing with different life situations. The findings of Pirasteh Motlagh and Nikmanesh [21] show a significant positive relationship between spirituality and quality of life and a significant negative relationship between spirituality and the feeling of suffering. Azargoon et al. [22] emphasized the effectiveness of mindfulness-based interventions in the relief of chronic pain. However, the issues of the quality of life in chronic diseases have been often neglected. Even though tuberculosis is common in Iran like other parts of the world and special attention to both medical and psychological dimensions is necessary for its control, the attempts and measures have mainly focused on medical care and neglected the related psychological factors. This study aims to predict the life quality of patients with TB based on consciousness variables, spiritual experiences, and coping strategies.

\section{Methods}

This is a descriptive correlational study in which mindfulness, spirituality, and coping strategies are considered as the predictors and the quality of life as the criterion variable. The research population includes all the 152patients with tuberculosis referring to the Zabol city tuberculosis center in 2015. The selected sample size in this study was 109 subjects by using Cochran formula and with the loss of some of the questionnaires, only 100 questionnaires were included in this study. Out of 100 patients, 48 were men and 52 were women. Nine percent of the subjects were between 10 and $20,55 \%$ between 20 and 40 , and $36 \%$ over 40 years old.

The inclusion criterion was referring to the Tuberculosis Center at least twice during 2015. During the following weeks, we selected our participants through a random sampling method from the Tuberculosis Center. The data collection took about one month with anonymously designed questionnaires and the Tuberculosis Center cooperation. Descriptive methods, the Pearson correlation coefficient, and stepwise regression analysis were used to analyze the data. The following questionnaires were used to collect the data:

\section{Five Facet Mindfulness Questionnaire (FFMQ)}

Five facet mindfulness questionnaire (FFMQ) is a 39item self-report scale. It has been developed by Bauer et al. (2006) and uses factor analysis. Alpha coefficients were acceptable and ranged between 0.55 related to non- reactive factor and 0.83 related to the description factor [23]. The subjects had to rate their agreement or disagreement with each one of the expressions on a 5-point Likert scale ranging from 1 (never or very rarely) to 5 (very often or always). A total score is calculated with summing the scores of each subscale. The total score ranges 39-150. A higher score indicates a higher rate of mindfulness. The measured subscales include observation, lack of reaction, lack of judgment, and describing the action with awareness [24].

\section{World Health Organization Quality of Life Ques- tionnaire (WHOQOL)}

This questionnaire is a short-form scale developed by the World Health Organization Quality of Life group in 1998. The questionnaire includes 26 questions that measure the following four areas: physical health, mental health, social relations, and environmental health. The answers to the questions are rated based on a 5-point Likert-type scale. In Iran, Nasiri and Razavi [25] calculated its Cronbach alpha coefficient as 0.84 . In the research conducted by Fathi and Ashtiani, the reliability of the questionnaire was 0.95 by using the Cronbach alpha method [26].

Ghobary, Gholamali, Lavasani, and Mohammadi's Spiritual Experiments Questionnaire

This spiritual experiment questionnaire is rated based on a 7-point scale and the answerers range from totally disagree to agree. Some questions are scored directly and some inversely. The credit factor of this questionnaire is 0.94 . It has been reported that this questionnaire has the appropriate content validity [27]

\section{Lazarus and Folkman Ways of Coping Question- naire (WOCQ)}

Lazarus and Folkman ways of coping questionnaire (WOCQ) is a 66-item questionnaire and was developed by Lazarus and Folkman. It assesses thoughts and actions. WOCQ is used by people to cope with stressful encounters in daily life and it is scored on a 4-point scale (never, sometimes, usually, much often). Zarei and Asadi (2012) reported the Cronbach's alpha value of $83 \%$ in their study for addicted young groups [28].

\section{Results}

The summary of data analysis is presented in Table 1 . The result of data normalization has been shown. Tables 2 and 3 report the acquired result of variable predictions. 
Table 1 shows the significant level of all research variables higher than 5\% indicating that the data distribution of the variables is within the $95 \%$ confidence normal. Table 2 shows a positive and significant relationship between mindfulness, spiritual experience, and coping strategies with life issues with the quality of life $(\mathrm{P} \leq 0.01)$, and dangers to the life quality of life are negative and significant $(\mathrm{P} \leq 0.05)$.

As shown in Table 3, the standard coefficients or beta are statistically significant $(\mathrm{P} \leq 0.01)$. Therefore, the findings show that the variables of mind-awareness, spiritual experience, and coping strategies can predict the quality of life variable. The standard coefficient or beta variable of mindfulness is higher compared with spiritual experience and problem-focused coping strategies. So, the mind-consciousness variable predicts the variable of the problem-oriented opposition, predicts the quality of life variable, and is the leading variable.

\section{Discussion}

The research revealed a positive and significant relationship between mindfulness and quality of life. This component explains $29 \%$ of the variance of the quality of life. This finding is consistent with the findings of Kaviani et al [29] and Roth and Robins [30]. Mindfulness means being in the moment with what is going on now, without judgment, and without comment on what is happening. Mindfulness is the stark reality experience, without explanation, [31] of quality of life includes life satisfaction. Mindfulness might lead to a positive attitude and consequently life satisfaction by influencing the individual's emotions and feelings. By reducing stress, mindfulness provides satisfaction for people and promotes the quality of life. Mindfulness requires planful awareness, the growth of judgment avoidance, and focus on the present moment by individuals. The individual's attention to the present moment leads to processing all

Table 1. One-sample Kolmogorov-Smirnov Test

\begin{tabular}{|c|c|c|c|c|c|c|}
\hline \multicolumn{2}{|r|}{ Variables } & $\begin{array}{l}\text { Problem-oriented } \\
\text { Coping Strategies }\end{array}$ & $\begin{array}{l}\text { Emotion-ori- } \\
\text { ented Coping } \\
\text { Strategies }\end{array}$ & $\begin{array}{l}\text { Spiritual } \\
\text { Experi- } \\
\text { ences }\end{array}$ & Mindfulness & $\begin{array}{c}\text { Quality of } \\
\text { Life }\end{array}$ \\
\hline \multicolumn{2}{|r|}{$\mathrm{N}$} & 100 & 100 & 100 & 100 & 100 \\
\hline \multirow{2}{*}{ Normal } & Parameters a, b Mean & 59.60 & 51.00 & 257.4 & 61.7 & 85.39 \\
\hline & Standard Deviation & 60.1 & 61.81 & 66.2 & 10.00 & 45.13 \\
\hline \multirow{3}{*}{$\begin{array}{l}\text { Most Ex- } \\
\text { treme }\end{array}$} & $\begin{array}{l}\text { Differences } \\
\text { Absolute }\end{array}$ & 0.080 & 0.074 & 0.059 & 0.075 & 0.021 \\
\hline & Positive & $\backslash 0.052$ & 0.074 & 0.059 & 0.075 & 0.021 \\
\hline & Negative & -0.080 & -0.064 & -0.056 & -0.075 & -0.11 \\
\hline \multicolumn{2}{|c|}{ Kolmogorov-Smirnov Z } & 0.094 & 0.834 & 0.669 & 0.841 & 0.522 \\
\hline \multicolumn{2}{|c|}{ Asymp. Sig. (2-tailed) } & $0.380 \mathrm{c}$ & $0.490 \mathrm{c}$ & $0.762 \mathrm{c}$ & $0.478 \mathrm{c}$ & $0.621 c$ \\
\hline
\end{tabular}

* Correlation is significant at the level of 0.05 .

uRA

** Correlation is significant at the level of 0.01 .

Table 2. The Results of Correlation Coefficient between mindfulness, spiritual experiences, and coping strategies of Quality of Life

\begin{tabular}{ccccccc}
\hline Variables & $\mathbf{1}$ & $\mathbf{2}$ & $\mathbf{3}$ & $\mathbf{4}$ & $\mathbf{5}$ & $\mathbf{6}$ \\
\hline Mindfulness & 1 & & & & & \\
\hline Spiritual experiences & 0.27 & 1 & & & & \\
Problem-oriented coping strategies & 0.34 & 0.23 & 1 & & & \\
\hline Emotion-oriented coping strategies & 0.37 & 0.34 & 0.25 & 1 & & 1 \\
\hline Quality of life & $0.632^{* *}$ & $0.525^{* *}$ & $0.231^{* *}$ & $-0.156^{*}$ & $0.632^{* *}$ & 1 \\
\hline Mindfulness & 0.21 & 0.47 & 0.29 & 0.29 & & \\
\hline
\end{tabular}


Table 3. Results of multiple regression analysis to predict the quality of life by resiliency, spirituality and coping strategies

\begin{tabular}{cccccc}
\hline Predicting Variables & $\mathbf{R}^{2}$ & $\mathbf{F}$ & $\mathbf{B}$ & $\mathbf{t}$ & Sig. \\
\hline Mindfulness & 0.29 & 147.42 & 11.5 & 9.9 & 0 \\
Spiritual experiences & 0.39 & 73.122 & 2.41 & 3.1 & 0.001 \\
\hline Problem-focused coping strategies & 0.411 & 104.54 & -3.42 & 3.3 & 0 \\
\hline
\end{tabular}

aspects of immediate experience, including cognitive, physiological, and behavioral activities.

Due to mindfulness-based practices and techniques, an individual can be aware of daily activities as well as the automatic function of mind in the past and future. Through the immediate awareness of the thoughts, feelings, and physical status, the person will get control over them and releases the daily and automatic focusing on the past and future [32]. Mindfulness-based interventions aimed to reduce the psychological symptoms of distress and enhance the quality of life. They are progressively applied in the field of mental health as well as physical health [33].

A positive and significant correlation was found between spiritual experiences and quality of life and spiritual experiences together with mindfulness can predict $39 \%$ of the variance of the quality of life. Quality of life can be divided into four dimensions of physical, mental, social, and spiritual functions, and each dimension has its components. The components of spiritual function include religious activities such as praying, worshiping God, and visiting holy and religious places (Berger Portnoi and Vissman, 1989) [28]. Prisla Ücker et al. [32] research results showed a significant relationship between physical dimensions and social relations of quality of life and spiritual well-being in patients with AIDS. The findings of Trevino et al. [33], Moalemi et al. [6] proved that religious and spiritual beliefs and activities act as supportive factors or buffer and could reduce stress which would enhance the quality of life in individuals with chronic diseases through raising hope and strength, and makes life meaningful.

There is a positive and significant relationship between problem-based coping strategies $(\mathrm{r}=0.231)$ and quality of life ( $\mathrm{P}=0.001)$. Also, there is a negative and significant relationship between emotion-based coping strategies $(\mathrm{r}=-0.156)$ and quality of life. The problem-based coping strategies along with variables of mindfulness and spiritual experiences predict $41.1 \%$ of the variance of the quality of life, but emotion-based coping strategies do not make any prediction. The findings of this study are consistent with the results of the research conducted by Kheirabadi et al. [16], Momeni and Shahbazi Rad [34], and Nedaei et al. [35].

There was no significant relationship between emotionbased coping strategies and quality of life. Problem-focused coping strategies and quality of life have a statistically significant relationship but this is inconsistent with the findings of Maleki et al. [36]. According to Lazarus and Folkman's pattern in the coping process, an individual uses cognitive skills to solve the problems by using a problem-based coping strategy. In this strategy, the ways to cope with the problem will be examined. With finding a good solution to the problem, a psychological satisfaction for the individuals will be achieved. Also, satisfaction and the increase in the quality of life can be the product of this coping process. Besides, the use of problem-based coping strategy reduces the level of stress in individuals and lower levels of stress can lead to proper use of cognitive skills. Meanwhile, an increase in mental peace can achieve more satisfaction in coping with problems.

Ultimately, the use of a problem-based coping strategy will be followed by an increase in quality of life [37]. However, denial and passivity are the characteristics of those who use inefficient emotion-based coping strategies. An emotion-based strategy is another way to include the thoughts or activities that are used to control undesirable emotions resulting from stressful conditions [38]. Choosing the right ways to cope with psychological pressure can reduce the effect of stress on mental health or lead to psychological adjustment. Different studies have shown that coping strategies have a significant role in modulating or enhancing the quality of life of patients with rheumatoid arthritis, intestinal infections, and heart disease [39]. Denying a stressful situation can lead to avoiding and distancing from them. 


\section{Conclusion}

Chronic diseases such as tuberculosis are one of the most important issues of modern societies which can decrease the quality of life of the patients as well as their mental health. Studying this disease and the psychological factors affecting it leads to the use of more comprehensive and advanced approaches in their planning and treatment processes. It is recommended that the healing process of patients with tuberculosis should not be just limited to a physiologic approach. The treatment process will be more efficient and long-lasting when the role of psychological factors are considered in the etiology and treatment.

Therefore, more comprehensive steps will be taken in the treatment of psychosomatic disorders through collaboration with physicians and psychologists. To maintain and enhance the mental health of individuals, families, and communities, it is recommended to pay more attention to different aspects of spirituality and their improvement. This research had some limitations. For instance, the referring patients were examined from all age groups. As the individuals grow older their experiences will increase and might affect the coping strategies, the use of mindfulness techniques as well as the efficiency of their spiritual experiences.

Since a paper-and-pencil questionnaire was used to collect data, the current study faced all restrictions related to measuring tools, whichcan be mentioneed as a study limitations.

\section{Ethical Considerations}

\section{Compliance with ethical guidelines}

All procedures were performed following the standards of the institutional research committee (4-11-1-1-16812) and the ethical Code of 5/947.

\section{Funding}

This research did not receive any specific grant from funding agencies in the public, commercial, or non-profit sectors.

\section{Authors' contributions}

All authors contributed in designing, running, and writing all parts of the research.

\section{Conflict of interest}

The authors declared no conflict of interest.

\section{References}

[1] Nasehi M, Mirhaghaani L. Guideline for control TB. $2^{\text {th }}$ ed. Tehran: Andishmand Press; 2009.

[2] Kumar V, Abbas AK, Fausto N, Mitchell RN. [Robbins Basic Pathology (Persian)]. $8^{\text {th }}$ ed. Saunders Elsevier; 2007.

[3] Hoseindokht A, Fathi Ashtiyani A, Taghazadeh ME. [The relationship between spiritual intelligence and spiritual wellbeing and quality of life and marital satisfaction (Persian)] Ravanshenasi Va Din. 2013; 6(2):57-74. https://www.sid.ir/ en/Journal/ViewPaper.aspx?ID=376873

[4] Mohr WK. Spiritual issues in psychiatric care. Perspective in Psychiatric Care. 2006; 42(:3)174-83. [DOI:10.1111/j.17446163.2006.00076.x] [PMID]

[5] Ghobaribanab B, Motavalipour A, Hakimirad E, Habibi AAM. [The relationship between anxiety and depression with the spirituality of Tehran University students (Persian)]. Journal of Applied Psychology. 2009; 3(2):110-23.

[6] Moalemi S, Raghibi M, Salari Z. Comparing spiritual and mental health in addicts and non-addicts. Journal of Shaheed Sadoughi University of Medical Sciences. 2010; 3(1):235-242.

[7] Ghofrani FA. [Examine the role of spiritual intelligence in the Quality of Life for students (Persian)]. Presented at: National Mental Health Conference. 2011; Islamic Azad University of Ghochan Branch, Iran.

[8] Alah Bakhshiyan M. Jafarpoor Alavi M. Parvizii SO. Haghani H. [The spiritual well-being and quality of life in patient with Multiple Sclerosis (Persian)]. Doctor East. 2008; 3:29-33.

[9] Golpour Chamarkohi R, Mohamadamini Z. [The efficacy of mindfulness based stress reduction on mindfulness and assertiveness of students with test anxiety (Persian)]. School Psychology. 2012;1(3):82-100.

[10] Kabat-Zinn J. Full catastrophe living: Uusing the wisdom of your body and mind to face stress, pain, and illness. New York: Delacourt; 1990.

[11] Sajadiyan I, Akrami N. [The reliance on God and other approaches to cope with anxiety in secondary school students (Persian)]. Knowledge and Research in Applied Psychology. 2006; 30 .

[12] Heidari M, Marvati ZA, Farshchi N, Khanbabaei R. The role of mindfulness, general self-efficacy and emotional intelligence in predicting perceived stress in female students. Health Technology Assessment. 2017; 15(1):6-7. http://journal.alzahra.ac.ir/article 2844.html

[13] Babaei Nadinluye K, Mikaeli Manee F, Pezeshki H, Bafande $\mathrm{H}$, Abdi $\mathrm{H}$. Relationship between mindfulness and meta-emotion on predicting emotional adjustment of Novice Nurses. Iranian Nursing Journals. 2017; 30(105):11-22.

[14] Duan W. Mediation role of individual strengths in dispositional mindfulness and mental health. Personality and Individual Differences. 2016; 99:7-10. [DOI:10.1016/j. paid.2016.04.078]

[15] Bamber MD, Schneider JK. Mindfulness-based meditation to decrease stress and anxiety in college students: A narrative 
synthesis of the research. Educational Research Review. 2016; 18:1-32. [DOI:10.1016/j.edurev.2015.12.004]

[16] Kheirabadi G, Bagherian R, Nemati K, Daghaghzadeh $\mathrm{H}$, Maracy M, Gholamrezaei A. [The effectivenessof coping strategies training on sympotom severity , quality of life and psychological symptom among patients with irritable bowel syndrome (Persian)]. Journal of Isfahan Medical School. 2010; 28(110):473-83.

[17] Tamizi Z, Ranjbar FA, Yaghmaei F, Alavi Majd H, Falahi Koshknab M. [The relationship between Quality of Life and coping strategies in schizophrenic patients admitted to psychiatric clinics of teaching hospitals in Tehran (Persian)]. Quarterly Journal of Rehabilitation. 2013; 13(4):124-31.

[18] Nejadahmadi N, Moradi A. The relationship between mindfulness, coping strategies and perceived stress on the quality of life of cancer patients. 2014; 35(9):171-88.

[19] Nohi E, Abdolkarimi M, Rezaeian M. Quality of Life and its relationship with stress and coping strategies in coronary heart disease patients. Journal of Rafsanjan University of Medical Sciences. 2011; 10(2):127-37.

[20] Azad Marzabadi E, Hooshmandja M, Poorkhalili M. [The relationship between organizational spirituality with psychological empowerment, creativity, intelligence, job stress and job satisfaction university (Persian)]. Behavioral Sciences. 2012; 20:181-88

[21] Pirasteh Motlagh AK, Nikmanesh Z .The relationship of spirituality with the pain and Quality of Life in patients with HIV/AIDS. Armaghan-e Danesh, Yasuj University of Medical Sciences Journal 2012; 17(4):337-48.

[22] Azargoon H, Kajbaf M, Molavi H, Abedi M. [The effectiveness of mindfulness in reducing depressive rumination and university students (Persian)]. Journal of Behavior. 2009; 16(34):13-20.

[23] Dehghani M, Esmaeilian N, Akbari F, Hassanvand M, Nikmanesh E. Evaluating the psychometric properties and factorial structure of the five dimensional mindfulness questionnaire. Thoughts And Behaviors In Clinical Psychology. 2013; 9(33):77-86.

[24] Ahmadvand Z, Heydarinasab L, Shairi MR. [Prediction of psychological well -being based onthe comonents of mindfulness (Persian)]. Health Psychology. 2012; 1(2):60-7.

[25] Nasiri H, Razavieh A. [Evaluating life quality of Shiraz University student (Persian)]. Based on the Proceedings of the Third Universal Seminar on students mental health. 2006; 145.

[26] Fathi Ashtiyani A. [Psychological testing (assessment of personality and mental health) (Persian)]. Tehran: Besat; 2009.

[27] Ghobaribanab B, Gholamali Lavasani M, Mohamadi M. Construction scale spiritual experience (Persian)]. Journal of Psychology. 2005; 9(3):34-37.

[28] Zarei S, Asadi Z. [The comparison of personality characteristics and coping styles in addicted and non-addicted adolescents (Persian)]. 2012; 5(20):87-104.

[29] Kaviyani H, Hatami N, Shafiabadi A. [The effects of mindfulness-based cognitive therapy on quality of life in depressed patients (nonclinical) (Persian)]. Advances in Cognitive Science. 2009; 10(4):39-48.
[30] Roth B, Robbins D. Mindfulness-based stress reduction and health-related quality of life: Findings from a bilingual inner-city patient population. Psychosomatic Medicine. 2004; 66(1):113-23. [DOI:10.1097/01.PSY.0000097337.00754.09] [PMID]

[31] Kabat-Zinn J. An outpatient program in behavioral medicine for chronic pain patients based on the practice of mindfulness meditation: Theoretical considerations and preliminary results. General Hospital Psychiatry. 1982; 4(1):33-47. [DOI:10.1016/0163-8343(82)90026-3]

[32] Prisla Ücker C, Marisa Campio M, Maria Lúcia NT. Quality of life and spiritual well-being in individuals with HIV/ AIDS. Psicolestud. 2008; 13(3):523-30.

[33] Trevino KM, Pargament KI, Cotton S, Leonard AC, Hahn $\mathrm{J}$, Caprini-Faigin CA, et al. Religious coping and physiological, psychological, social, and spiritual outcomes in patients with HIV/AIDS: Cross-sectional and longitudinal findings. AIDS and Behavior. 2010; 14(2):379-89. [DOI:10.1007/s10461007-9332-6] [PMID]

[34] Momeni KM, SHahbazi Rad A. [The relationship between spirituality, resilience and coping strategies and quality of life (Persian)]. Behavioral Sciences. 2012; 6(2):97-103.

[35] Nedaei A, Paghoosh A, Sadeghi-Hosnijeh AH. Relationship between coping strategies and Quality of Life: Mediating role of cognitive emotion regulation skills. Clinical Psychology. 2016; 8(4):35-48. [DOI:10.22075/JCP.2017.2252]

[36] Maleki H, Maleki Y. Interaction of Ethics, Spirituality, and Rationality in the New Islamic Civilization. Irainian Journal of the Knowledge Studies in the Islamic University. 2013; 17(57):593-616.

[37] Astin C, Vieten JE. Effects of a mindfulness-based intervention during pregnancy. Archives of Women's Mental Health. 2008; 11(1):67-74 [DOI:10.1007/s00737-008-0214-3] [PMID]

[38] Prasertsri N, Holden J, Keefe FJ, Wilkie DJ. Repressive coping style: Relationships with depression, pain, and pain coping strategies in lung cancer out patients. Journal of Lung Cancer. 2011; 71(2):235-40. [DOI:10.1016/j.lungcan.2010.05.009] [PMID] [PMCID]

[39] Pourang PA, Besharat MO. An investigation of the relationship between coping styles and psychological adaptation with recovery process in a sample of coronary heart disease patients. Procedia - Social and Behavioral Sciences. 2011; 30:171-5. [DOI:10.1016/j.sbspro.2011.10.034] 
This Page Intentionally Left Blank 